\title{
Local Generation and Propagation of Ripples along the Septotemporal Axis of the Hippocampus
}

\author{
Jagdish Patel, ${ }^{1,2}$ Erik W. Schomburg, ${ }^{2,4}$ Antal Berényi, ${ }^{2,5}$ Shigeyoshi Fujisawa, ${ }^{1,2}$ and György Buzsáki ${ }^{1,2,3}$ \\ ${ }^{1}$ Center for Molecular and Behavioral Neuroscience, Rutgers, The State University of New Jersey, Newark, New Jersey 07102, ${ }^{2}$ The Neuroscience Institute, \\ School of Medicine and ${ }^{3}$ Center for Neural Science, New York University, New York, New York 10016, ${ }^{4}$ Physics Department, California Institute of \\ Technology, Pasadena, California 91125, and ${ }^{5}$ Department of Physiology, University of Szeged, Szeged H-6720, Hungary
}

\begin{abstract}
A topographical relationship exists between the septotemporal segments of the hippocampus and their entorhinal-neocortical targets, but the physiological organization of activity along the septotemporal axis is poorly understood. We recorded sharp-wave ripple patterns in rats during sleep from the entire septotemporal axis of the CA1 pyramidal layer. Qualitatively similar ripples emerged at all levels. From the local seed, ripples traveled septally or temporally at a speed of $\sim 0.35 \mathrm{~m} / \mathrm{s}$, and the spatial spread depended on ripple magnitude. Ripples propagated smoothly across the septal and intermediate segments of the hippocampus, but ripples in the temporal segment often remained isolated. These findings show that ripples can combine information from the septal and intermediate hippocampus and transfer integrated signals downstream. In contrast, ripples that emerged in the temporal pole broadcast largely independent information to their cortical and subcortical targets.
\end{abstract}

\section{Introduction}

During immobility, consummatory behaviors, and slow-wave sleep (SWS), coincidental activity at multiple locations in the excitatory recurrent networks of the hippocampal CA3 region gives rise to a convergent depolarization of the CA1 neurons (i.e., the sharp wave; Buzsáki et al., 1983). The excitatory drive, in turn, triggers a fast oscillatory event $(140-180 \mathrm{~Hz})$ known as a "ripple" that arises via local interactions between the CA1 pyramidal cells and interneurons (O'Keefe and Nadel, 1978; Buzsáki et al., 1992; Ylinen et al., 1995; Csicsvari et al., 2000). Neuronal composition of the sharp-wave ripple (SPW-R) is influenced by previous experience (Buzsáki, 1989; Wilson and McNaughton, 1994; Skaggs and McNaughton, 1996; Kudrimoti et al., 1999; Nádasdy et al., 1999; Lee and Wilson 2002; Foster and Wilson, 2006; O’Neill et al., 2006, 2008; Diba and Buzsáki, 2007; Karlsson and Frank, 2008, 2009; Singer and Frank, 2009; Dupret et al., 2010; but see Dragoi and Tonegawa, 2011, 2013). Mainly because of the effective hippocampal-neocortical communication during ripples and their behaviorally relevant spike content, SPW-Rs have been postulated to play an important role in memory consolidation (Buzsáki, 1989, 1996; Wilson and McNaughton, 1994; McClelland et al., 1995; Siapas and Wilson, 1998; Ji and Wilson, 2007; Axmacher et al., 2008; Eschenko et al., 2008; but see Lubenov and Siapas, 2008; Mölle and Born, 2009; Ramadan et al., 2009). In

Received May 14, 2013; revised Sept. 12, 2013; accepted Sept. 17, 2013.

Author contributions: J.P. and G.B. designed research; J.P. and A.B. performed research; J.P., E.W.S., A.B., and S.F. contributed unpublished reagents/analytic tools; J.P., E.W.S., and G.B. analyzed data; J.P. and G.B. wrote the paper.

This work was supported by National Institute of Health Grants NS34994, MH54671, and NS074015, National Science Foundation Grant SBE 0542013, the Human Frontier Science Program, and the James S. McDonnell Foundation. We thank A. Amarasingham for comments on this manuscript.

Correspondence should be addressed to György Buzsáki at the above address. E-mail: gyorgy.buzsaki@nyumc.org. DOI:10.1523/JNEUROSCI.2036-13.2013

Copyright $\odot 2013$ the authors $\quad 0270-6474 / 13 / 3317029-13 \$ 15.00 / 0$ support of this hypothesis, selective elimination of ripples during postlearning sleep results in impairment of memory performance (Girardeau et al., 2009; Ego-Stengel and Wilson, 2010; Nokia et al., 2012). Despite progress on the potential physiological-behavioral role of ripples, it is not well understood what fraction of neurons along the septotemporal axis of the hippocampus is engaged during the ripple events and whether ripple events remain largely localized or engage multiple segments along this axis (Ylinen et al., 1995; Chrobak and Buzsáki, 1996). Such information is critical since it provides important information as to whether the different segments of the structure send outputs to different streams or whether sharp waves combine intrahippocampal information from all segments and transmit this combined pattern.

Several previous experiments have emphasized physiological differences between different segments of the hippocampus along its septotemporal axis (Jung et al. 1994; Deadwyler et al. 1996; Wiener, 1996; Hampson et al., 1999; Maurer et al. 2005; Lubenov and Siapas, 2009; Royer et al., 2010; Segal et al., 2010; Adhikari et al., 2011; Patel et al., 2012; also referred to as the dorsoventral or longitudinal axis). However, the conditions that confine or allow for the propagation of ripple events along the septotemporal axis are largely unknown (Ylinen et al., 1995; Chrobak and Buzsáki, 1996; Csicsvari et al., 2000). Since projections from different segments of the hippocampus communicate with different structures, such as the subiculum, amygdala, and different territories of the neocortex via the entorhinal cortex (cf. Amaral and Lavenex, 2007; Ranganath and Ritchey, 2012), ripples that emerge from the septal, intermediate, and temporal segments of the CA1 region may broadcast different information to their targets at the same or different times. To examine the spatial organization of SPW-R patterns, we recorded local field potential (LFP) and neuronal discharge activity along the entire septo- 

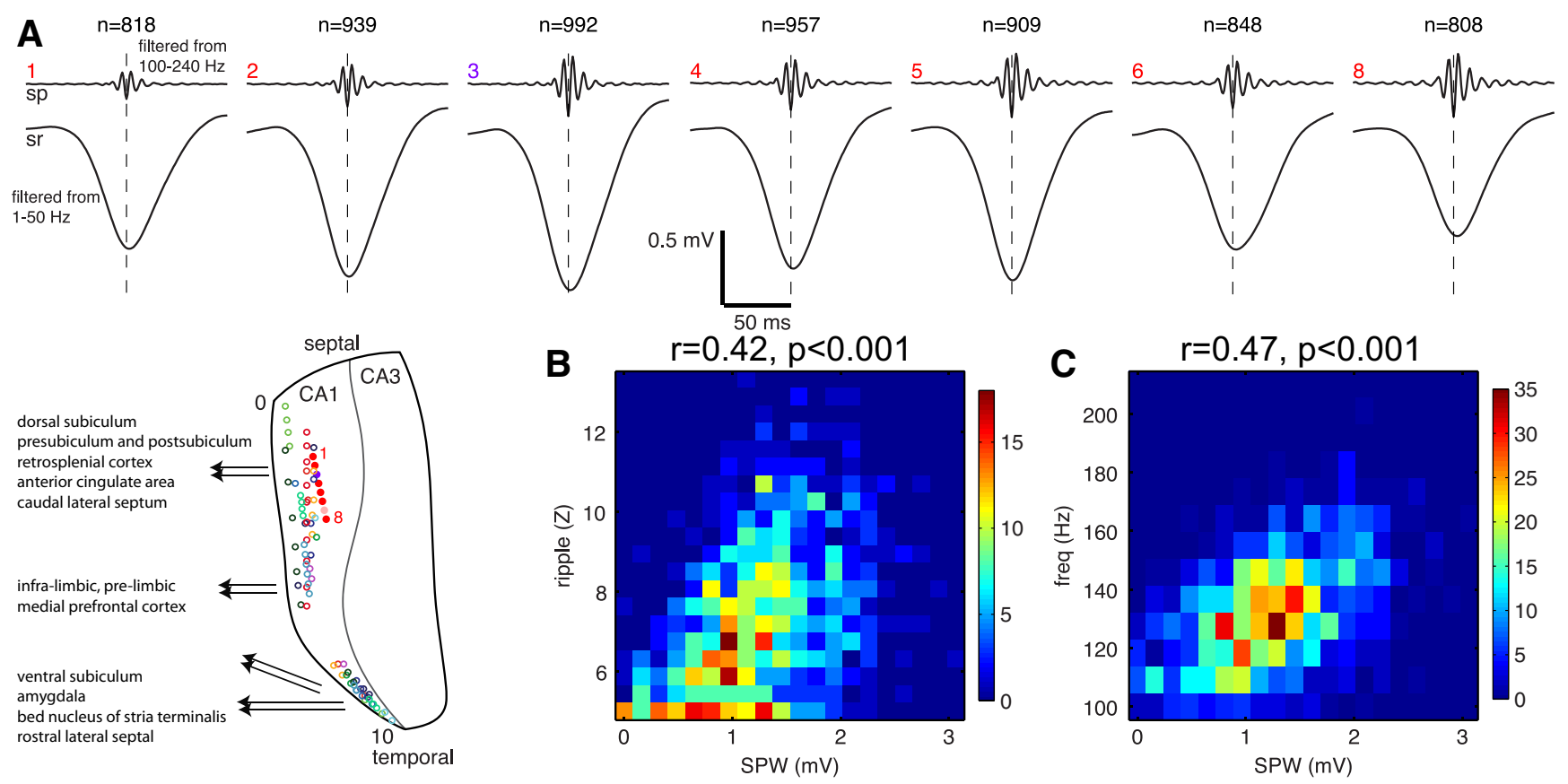

Figure 1. Sharp waves and ripples in the CA1 region. $\boldsymbol{A}$, Ripples and sharp waves recorded from seven pairs of sites (red dots in inset) in the pyramidal layer (sp) and middle of stratum radiatum (sr) along the septotemporal axis. Each pair is an independent average of $>807$ (actual number given on top of each shank) events, triggered by the trough of the largest amplitude ripple wave of the locally recorded ripple events. Flat map shows the location of the recording electrodes in the CA1 region. $\boldsymbol{B}$, Correlation between the peak amplitude of sharp waves and ripple magnitude (root mean square of the filtered event) measured between sites in the pyramidal layer and radiatum on shank 3 ( $A$, purple dot). Colors indicate the density of points. $C$, Correlation between the peak amplitude of sharp waves and ripple frequency (using same data as in $\boldsymbol{B}$ ). sp, stratum pyramidale; $s$, stratum radiatum.

temporal axis of the hippocampal CA1 pyramidal layer in sleeping rats.

\section{Materials and Methods}

\section{Animals and surgical procedures}

Data were collected from 15 Long-Evans rats (male, 250-400 g, 3-5 months old). The details of surgery and recovery procedures used have been described previously (Csicsvari et al., 1999; Patel et al., 2012). In brief, animals were deeply anesthetized with isoflurane, and up to four separate craniotomies were performed over the right hippocampus. The electrodes [six rats equipped with tetrodes, three rats with single $50 \mu \mathrm{m}$ tungsten wires, three rats with three silicon probes (Patel et al., 2012), two rats with two silicon probes, and one rate with an eight-shank 256-site probe] for recordings from the septal-intermediate CA1 segments were organized in a straight line and spanned up to a $6.5 \mathrm{~mm}$ distance. These arrays were inserted parallel with the septotemporal axis of the hippocampus so that the tips arrived in the CAl pyramidal layer at approximately the same distance from the subicular and CA3 borders at all septotemporal levels (Fig. 1A). All tetrodes, single wires, and silicon probes were independently movable. The septal-intermediate drive(s) were placed between $2.2 \mathrm{~mm}$ to $6.3 \mathrm{~mm}$ AP and $0.8 \mathrm{~mm}$ to $6.0 \mathrm{~mm}$ ML. Of the 15 animals, 14 also had a drive placed in the temporal segment (single electrodes, 2 rats; tetrodes, 2 rats; eight sites by four shank silicon probe, 10 rats), placed between $4.5 \mathrm{~mm}$ to $6 \mathrm{~mm}$ AP and $4 \mathrm{~mm}$ to $5.7 \mathrm{~mm}$ ML (Patel et al., 2012). For qualitative description of the collected physiological data, recording sites along the septotemporal axis were arbitrarily divided into septal $(0-3.25 \mathrm{~mm})$, intermediate $(3.26-6.5 \mathrm{~mm})$, and temporal $(8.0-10.0 \mathrm{~mm}$ ) segments (Patel et al., 2012). In all experiments, ground and reference screws were implanted in the bone above the cerebellum. After postsurgical recovery, recording electrodes were lowered over the course of several days in steps of $50 \mu \mathrm{m}$ or less, until large units and ripple activity were isolated at appropriate depths. In each rat, we simultaneously recorded from at least two sites in the septal/ intermediate CA1 pyramidal layer along the septotemporal axis, and from at least one site in the CA1 pyramidal layer in the temporal pole. All experiments were performed in accordance with protocols approved by the Institutional Animal Care and Use Committee of Rutgers University.

\section{Behavioral training}

All animals were handled and trained in two mazes (an open field and a zigzag maze) for at least 2 weeks before surgery (Royer et al., 2010). The same behavioral procedures were used for training and testing. Only sleep sessions were analyzed for the results presented here. All sessions were recorded while the rats slept in their home cages, once at the beginning of each day, then again following a behavioral session. Sleep session recordings were terminated if the rat awakened and moved, and continued only when the rat returned to uninterrupted sleep for at least $5 \mathrm{~min}$ after a minimum waiting period of $5 \mathrm{~min}$.

\section{Histological and physiological verification of recording sites}

Detailed procedures of the methods are the same as in our previous work (Patel et al., 2012). Briefly, the electrode tracks of both wire electrodes/ tetrodes and silicon probe shanks were determined from the histological sections. In all figures where electrode position is given, distance was measured from the septal end of the hippocampus, after taking into account the exact anatomical coordinates of the electrodes and the curvature of the hippocampus (Patel et al., 2012). Only data with verified electrode tracks and physiological recordings of ripples and unit firing were included in the analyses.

\section{Data acquisition, processing, and analysis}

During the recording sessions in 11 rats, neurophysiological signals were preamplified $(20 \times)$, bandpass filtered ( $1 \mathrm{~Hz}$ to $9 \mathrm{kHz}$ ), acquired continuously at $32 \mathrm{kHz}$ on a 128-channel DigiLynx System (24 bit resolution; NeuraLynx), and stored for off-line analysis. During recordings made from the additional four rats, the neurophysiological signals were preamplified $(400 \times)$, bandpass filtered $(0.3 \mathrm{~Hz}$ to 10 $\mathrm{kHz}$ ), multiplexed at the head stage, acquired continuously at $20 \mathrm{kHz}$ per channel on a 256 channel KJE-1001 system (Ampliplex), and stored for off-line analysis. LFP and unit activity were recorded in the home cage while the rat was sleeping. All electrodes were advanced independently until ripples (Buzsáki et al., 1992; O’Keefe 2007), associated with unit firing in the CA1 pyramidal layer, were detected during sleep in the home cage. During subsequent recording sessions, electrodes were further adjusted to obtain largest amplitude ripples, 
A

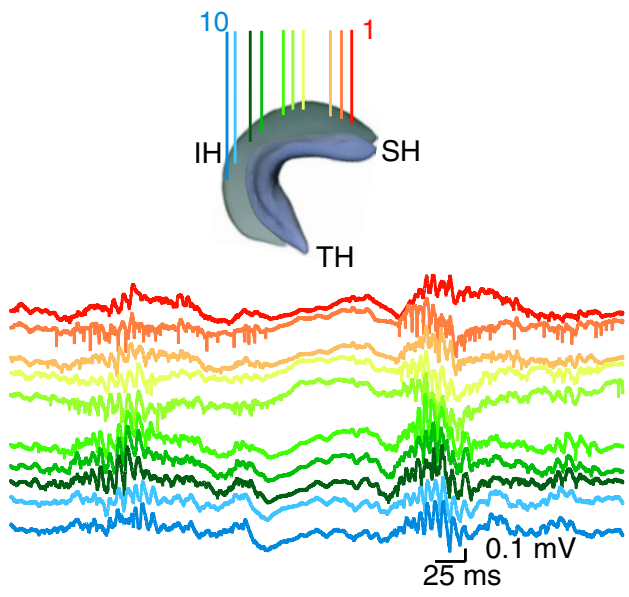

C

\section{D}

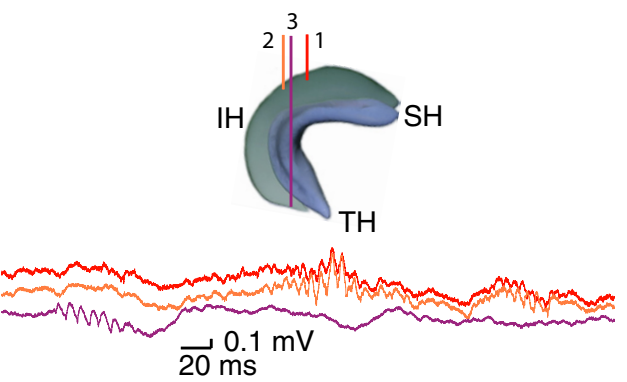

B

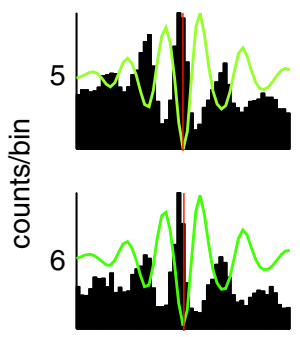

E
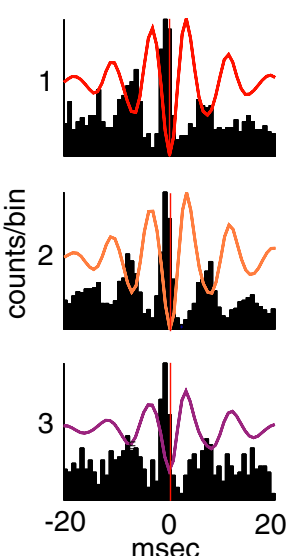
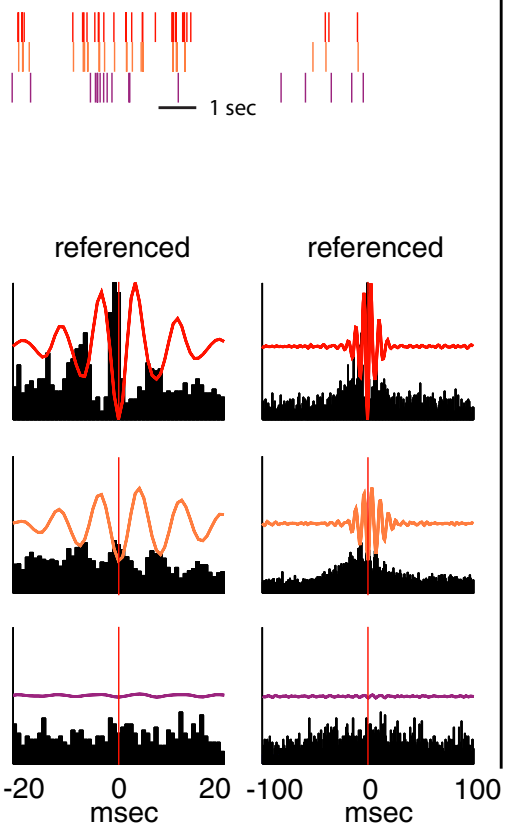

referenced
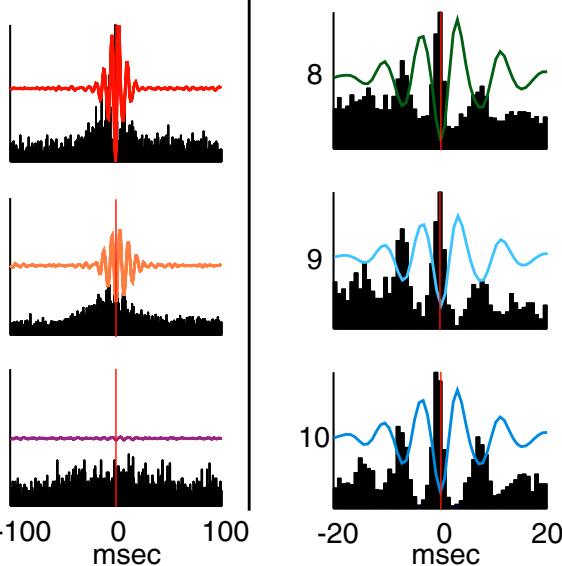
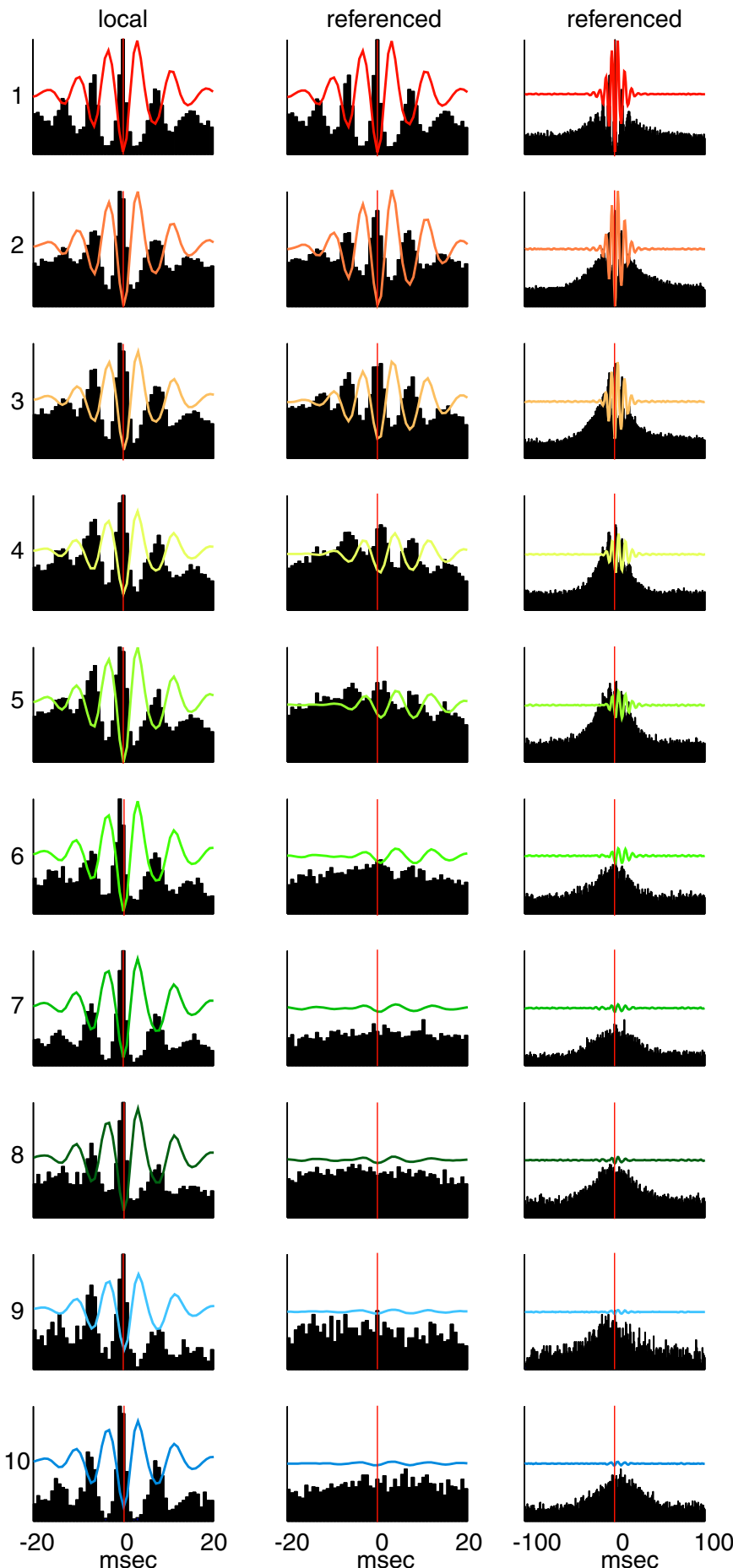

Figure 2. Ripples occur along the entire septotemporal axis of CA1. A, Diagram of the hippocampus indicating the locations of 10 recording electrodes along the septotemporal axis. SH, Septal hippocampus; IH, intermediate hippocampus; TH, temporal hippocampus. Ripples are recorded from the CA1 pyramidal layer as in $\boldsymbol{A}$. $\boldsymbol{B}$, Left, Ripple trough-triggered LFP (100 -250 Hz bandpass) and correlated multiple unit activity during ripples detected on each electrode (left; same color code as in $A$ ). Middle and right columns show averaged LFP and MUA, but the ripple event times were taken from the most septal reference site (1; reference). The two time scales emphasize ripple wave (middle) and ripple event (right) relationships. Note rapid loss of ripple wave modulation of neuronal firing with distance, whereas ripple events have a larger spatial spread. $\boldsymbol{C}-\boldsymbol{E}$, Same as in $\boldsymbol{A}$ and $\boldsymbol{B}$ but showing traces from two septal and one temporal CA1 pyramidal layer locations. $\boldsymbol{D}$, Temporal relationship of ripple events at the three locations. $\boldsymbol{E}$, Locally recorded LFP ripples and unit firing are similar at septal and temporal locations (left). In contrast, ripples recorded at septal sites and at the temporal tip of the CA1 region are largely independent (middle and right columns).

corresponding to the middle of the pyramidal layer (Mizuseki et al., 2011). In rats with silicon probe recordings, only sites with the maximum ripple power in the pyramidal layer were included for analysis (Patel et al., 2012). Only recordings that met the inclusion criteria (large-amplitude ripples with associated strong unit firing and subsequent anatomical verification of the recording tracks) were ana- lyzed further (59 of 119 recording sites in septal hippocampus and 24 of 54 recording sites in temporal hippocampus; $n=15$ rats; two to six sleep sessions per rat; see Experimental procedures; Patel et al., 2012). All raw data were preprocessed using the same custom-developed suite of programs (http://neuroscope.sourceforge.net/; Hazan et al., 2006). The wide-band signal was downsampled to $1252 \mathrm{~Hz}$ (or 1250 
$\mathrm{Hz}$ ) to generate the LFP, and was high-pass filtered $(>0.8 \mathrm{kHz})$ for spike detection. All data analyses were performed in Matlab (Mathworks).

Ripple event detection. The following stepby-step procedure was used for each individual session to detect ripple events in the LFP recordings. Ripple events refer to the entire series of ripple waves (presumably associated with a single sharp wave), and a distinction is made when individual ripple waves are compared (e.g., ripple wave synchrony; see Fig. 6).

(1) SWS periods were extracted from sleep recordings by removing REM theta periods, detected using the theta/delta power ratio (Csicsvari et al., 1999). SWS periods of $<4 \mathrm{~s}$ were further removed. The successful identification of SWS epochs was confirmed through visual inspection of the spectrogram (1-250 $\mathrm{Hz}$ ) along with the raw LFP signal of each sleep session for each rat. (2) The detected SWS periods from a given session were concatenated and narrow bandpass filtered between 100 and $250 \mathrm{~Hz}$. (3) The power (root mean square) of the filtered signal was calculated in a $17 \mathrm{~ms}$ sliding window for each electrode. (4) The mean and SD of the power signal were calculated to determine the detection threshold. (5) Oscillatory epochs with a power larger than $[1.5,2,3]$ SDs above the mean for at least $20 \mathrm{~ms}$ were detected. Each detected epoch was also required to cross a higher threshold of $\mathrm{SD} \geq[3$, 5 , or 7], respectively. The beginning and the end of the oscillatory epoch (i.e., duration of the ripple event) were marked at sample points at which the power reduced below the lower threshold values of 1.5, 2, and 3 SDs for ripples with a 3, 5, or 7 SD threshold. (6) The time of the peak integrated power was saved for each detected ripple event and in the vicinity of the peak of the integrated power the trough of the largest amplitude ripple wave was identified and saved. (7) Ripples were segregated in three nonoverlapping amplitude categories $[>7$, $5 \leq 7,3 \leq 5$ SDs]

Wavelet analysis. Wavelet transforms of the 100-250 Hz-filtered LFPs were generated using complex Morlet wavelets with bandwidth parameters $1.5 \times$ the center frequency ("cmor1.5-1" in the Matlab Wavelet Toolbox) for each detected ripple epoch for the $\pm 50 \mathrm{~ms}$ period surrounding the event times. Peak values from the wavelet transforms were defined as peak ripple amplitude values. Peak ripple frequency was identified as the peak frequency bin in which the wavelet transform peaked. Figure $3 D$ shows the mean of all such peak ripple frequencies for all locally detected ripples. Figure $3 E$ shows the same but for amplitude values.

Ripple synchrony measure. This analysis was conducted in pairs of electrodes, a reference and a referred electrode. Using ripple event times, defined by the largest ripple trough in the reference channel, we asked how often a ripple occurs in the referred channels within $\pm 1 \mathrm{~ms}$ of the ripple event times, and converted it to a percentage (ripple wave synchrony; see Fig. 6C). Next, we repeated the same analysis but with a wider time window of $\pm 50 \mathrm{~ms}$ to measure the ripple event synchrony (see Fig. 6D).

Relative ripple amplitude. This analysis was also conducted in electrode pairs. Using the detected ripple event times in the reference channel, we determined the mean concurrent Morlet wavelet amplitude values (in the 120 to $180 \mathrm{~Hz}$ band) in all referred channels. We plotted these mean values as a function of distance between the electrodes in the pair (see Fig. $6 E, F)$.

Unit analysis. Multiple unit activity was obtained by removing the noise cluster from the data and combining all spikes into a single spike series (Fig. 2). We measured the multi-unit activity (MUA) histograms surrounding the previously identified ripple event times $( \pm 20$ and \pm 100 ms; Fig. 2). Next we determined the gain in multiunit firing activity during ripples in electrode pairs. For this, we first measured the ratio of average firing within the $2 \mathrm{~ms}$ surrounding the ripple event times and the average firing rate in the $5 \mathrm{~ms}$ bins at $\pm 100 \mathrm{~ms}$. The gain in multiunit firing activity was plotted as a function of distance between electrodes for each electrode pair (see Fig. 7).

Permutation test. A permutation test was used to assess the statistical significance of the difference of ripple propagation speed slopes between ripple events detected with different SDs and ripples propagating in different directions. First, the regression coefficients between propagation speed and anatomical distances were calculated using a multiple linear regression model. Second, to form the surrogate data sets, each label (i.e., different SDs used to detect ripples or ripple propagation direction) of each data point in the original data set was randomly shuffled. Next, the regression coefficients were estimated for these surrogate data sets, and the difference of slopes for any two amplitudes/propagation directions were noted. This process was repeated independently to generate 10,000 counts of slope differences. Finally, the ripple speed difference was determined to be statistically significant if fewer than $5 \%$ of the shuffled differences were greater than the measured difference (see Fig. 8).

Three-way ANOVA. For calculating the statistical significance of ripple length, frequency, amplitude, and ripple rate values over location along the septotemporal axis, and for the factor of SDs used to detect ripples, multiway ANOVA (three-way ANOVA) method was used (Fig. 3).

\section{Results}

Ripples along the septotemporal axis of the CA1 pyramidal layer

Sharp-wave ripple complexes are initiated by the coincident discharge of pyramidal cells in the CA3 region. The CA3 output generates strong depolarization in the apical dendrites of CA1 pyramidal cells and interneurons, which is reflected extracellularly as a sharp wave in the stratum radiatum (Buzsáki et al., 1983; 
Sullivan et al., 2011; Fig. 1A). In turn, the interactions between CA1 pyramidal cells and interneurons give rise to a transient fast oscillation, the ripple (Buzsáki et al., 1992; Ylinen et al., 1995; Csicsvari et al., 2000). While sharp waves and ripples are distinct events (Buzsáki, 1986; Buhl and Buzsáki, 2005), their close relationship is reflected by the similar time course of the two events and the correlation between the amplitude of the sharp waves and the magnitude and frequency of the ripples (Buzsáki 1986; Sullivan et al., 2011; Fig. 1B,C). Because of the strong correlation between the two events, and because in most experiments only recordings from the CA1 pyramidal layer were available at multiple locations, the magnitude of the ripple episodes was used as a proxy for sharp waves in the quantification of their spread along the septotemporal axis. A ripple episode consists of multiple ripple waves (typically 4-10), whose envelope defines the ripple event. Therefore, we discuss the spatial relationship between ripple waves and ripple events separately.

To quantify ripples, high-frequency events were first detected independently at each recording site. Oscillatory episodes in which the amplitude of the ripple band-filtered trace (100-250 $\mathrm{Hz}$ ) was $>3$ SDs above the session background mean were identified as ripple events and subsequently separated into 3 to 5,5 to 7, and >7 SD groups (Csicsvari et al., 1999; see Materials and Methods). Figure 2, $A$ and $C$, illustrates recordings from the CA1 pyramidal layer at multiple sites in the septal, intermediate, and temporal segments of the hippocampus. Ripples emerged at each location with comparable amplitude, duration, and shape, but they showed large variability in their spatial profile across electrodes from event to event (Fig. 2A,C). When filtered LFP ripples $(100-250 \mathrm{~Hz} ;>7 \mathrm{SDs})$ and concurrent multiunit activity were compared at different locations, the locally recorded events were virtually identical at all recordings sites from the septal to the temporal pole of the CA1 pyramidal layer (Fig. $2 B, E$, left). When the LFPs and MUA firing histograms were aligned relative to ripple times at a single reference site, while the ripple wave coherence decreased precipitously with distance (Fig. $2 B$, middle), a broad ripple event-related increase in firing rates persisted for longer distances (up to $5.5 \mathrm{~mm}$; Fig. $2 \mathrm{~B}$, right). However, the ripple event-related increase in the septal hippocampus failed to spread to the temporal segment (Fig. 2E, right).

Next we quantified various ripple parameters, including duration, frequency, amplitude, and rate of occurrence, at different locations along the septotemporal axis. The duration of the ripple event was measured as the length of time that passed from the time point when the power of the filtered trace exceeded the lower SD threshold to the time point when it returned below the same lower $\mathrm{SD}$ threshold (Fig. $3 A, B$ ). The duration of ripples events increased as a function of the ripple event amplitude (Fig. $3 C ; p<0.001$; three-way ANOVA). The durations of ripple events within the same amplitude group were remarkably similar in the septal, intermediate, and temporal segments $(p=0.41$, location effect; septotemporal axis-SD group interaction, $p<$ 0.0002; three-way ANOVA). Within-ripple event frequency, quantified from the Morlet wavelet transform surrounding the ripple peak amplitude, showed a moderate but monotonic decrease from the septal to the temporal pole (Fig. $3 D ; p<0.001$, three-way ANOVA) and also depended on the magnitude of the ripple (Fig. $3 D$; SD group effect, $p<0.001$; septotemporal axis SD group interaction, $p<0.0005$; three-way ANOVA). The magnitude of the ripple event was determined from the Morlet wavelet transform in the $\pm 50 \mathrm{~ms}$ time window surrounding each ripple event and a mean across the number of ripples was measured (Fig. 3E; see Materials and Methods). The amplitude of the ripple event remained relatively constant or slightly decreased in the septal-intermediate axis, but was significantly lower in the temporal third (Fig. 3E; SD group effect, $p<0.001$; axis effect, $p<$ 0.001 ; axis-SD group interaction, $p<0.001$; three-way ANOVA). Ripple event rate (events per minute) showed a strong axis-SD group interaction (Fig. 3F; $p<0.001$; three-way ANOVA). In the septal and intermediate segments, both loweramplitude ( 3 to $5 \mathrm{SDs}$ ) and large-amplitude ( $\geq 7 \mathrm{SDs}$ ) events dominated, whereas in the temporal segment, smaller-amplitude ripples occurred most frequently (Fig. $3 F$ ). The septotemporal difference of rate in the $3 \mathrm{SD}$ groups could largely be explained by the decreased amplitude of the ripple events in the temporal segment.

\section{Spread of ripples along the septotemporal axis}

Our analysis above showed that ripples can be recorded at any location along the septotemporal axis, but it did not identify the origin of their emergence. Are ripples initiated at a preferred location, or can they emerge independently at any location? How do they spread from their starting point? To investigate these questions, we detected ripples (using the same threshold) at all recorded locations and sorted them according to the time of occurrence of the ripple peak. Visual analysis suggested that ripples could emerge at any level along the septotemporal axis (Fig. 4). From the seed, the activity could propagate toward both septal and temporal directions. Along the path of the travel, the amplitude of the ripple event could either increase or decrease nonmonotonically. Both the amplitude and spatial extent of ripple showed variability, from strongly localized to spatially widespread events (Figs. 4, 5). Ripples could emerge at two or more locations either relatively simultaneously or with delays. In such cases, certain recording locations were invaded from both directions, either giving rise to a prolonged or a double ripple event, or the earlier ripple could suppress the later arriving one. Occasionally, ripples appeared to "reflect" back in the opposite direction (Fig. 4), possibly due to a secondary seed. The event-to-event variability of propagation parameters amplitude, speed, and direction revealed a diversity in their physiological organization (Fig. 5). In this rat (Fig. 5), we determined the relative fraction of various events. Of all ripples detected in the septal-intermediate segment ( $n>4200$ ), $21 \%$ were designated as "local" (defined as ripples whose amplitude decreased to $10 \%$ of the peak value over $1 \mathrm{~mm}$ distance). Of the remaining "nonlocal" events, $38 \%$ were synchronous, $24 \%$ traveled in the temporoseptal, and $13 \%$ traveled in the septotemporal direction, with $4 \%$ of the ripples unclassified. These fractions should be considered as tentative since the behavior before sleep may significantly affect their distributions. In the ventral segment, the majority of ripples were local by the same criteria (as discussed below).

The above observations were further quantified by determining the probability of co-occurrence ("synchrony") and amplitude changes between pairs of recording sites at all available septotemporal distances (Fig. 6). Because of the similarity of ripples in the septal and intermediate segments (Fig. 3), pairs from these segments were combined as one group and compared to pairs that spanned both the septal/intermediate and temporal segments. In the first comparison ("ripple wave synchrony"), the fraction of co-occurring events was plotted as a function of distance (Fig. $6 C, D$ ), with event times defined by the trough of the largest ripple wave. Strongly synchronous ripple waves, as detected within a $\pm 1 \mathrm{~ms}$ window, were confined largely to neighboring sites. Coincident large-amplitude ripple waves $(>7 \mathrm{SD}$ events at both sites) occurred mainly at short distances, and the 


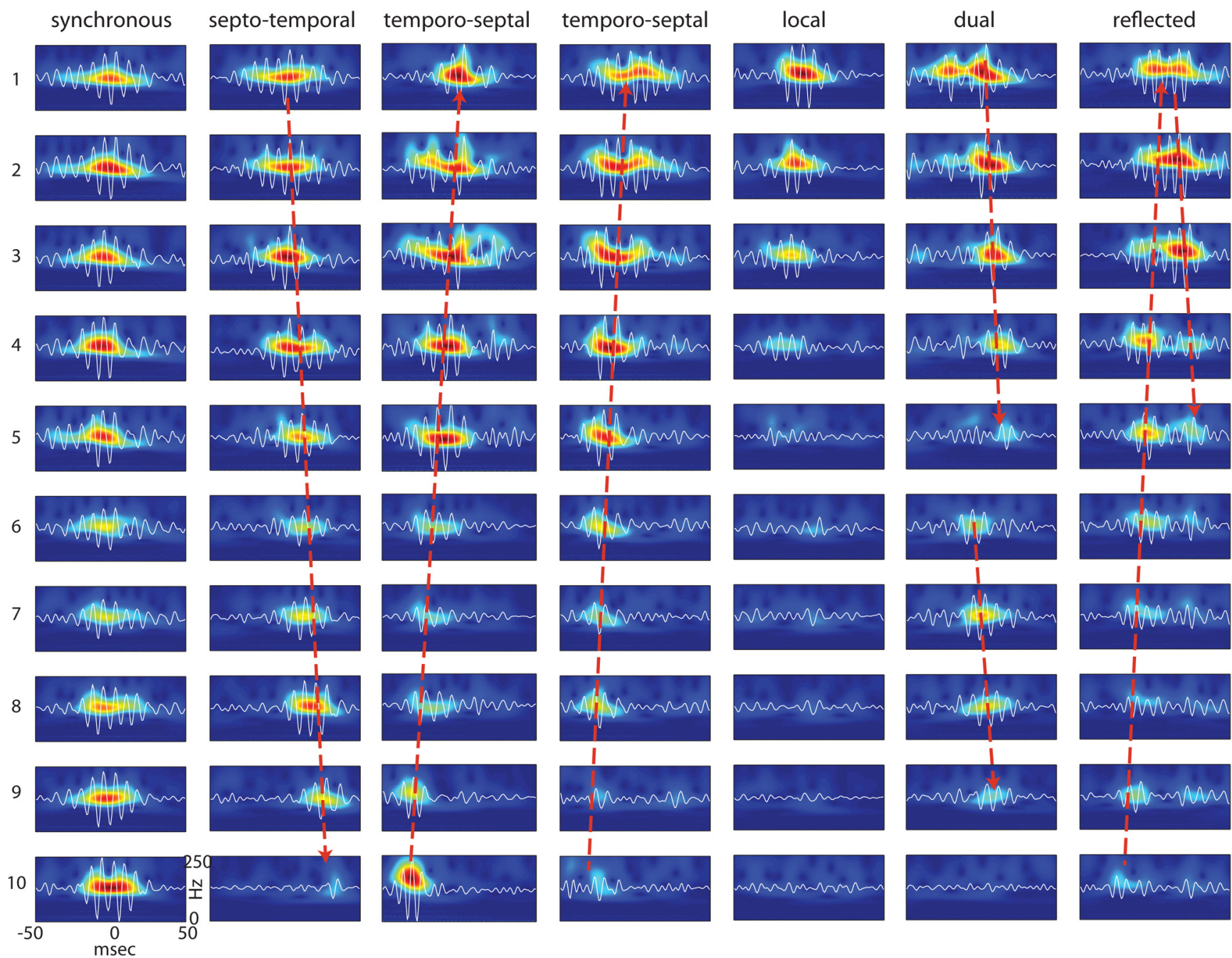

Figure 4. Spatial extent and propagation of ripple events. Examples of single ripple events and their wavelet maps recorded from 10 sites in the septal and intermediate segments of the hippocampus (as in Fig. 2). Ripple events can spread in a septotemporal or temporoseptal direction (long dashed arrows), but multiple other forms, such as synchronous, or locally confined events are also present. Occasionally, ripples emerge from two seeds simultaneously (dual; two arrows) or travel in opposite directions (reflected), leading to prolongation or doubling of ripple events at certain locations.

percentage of coincident ripple waves decreased with decreasing ripple event amplitude. Intermediate (5-7 SD events) and small (3-5 SD events) ripple waves were essentially noncorrelated at distances $>2 \mathrm{~mm}$ (Fig. 6C). We then quantified the cooccurrence of ripple events in $\pm 50 \mathrm{~ms}$ windows ("ripple event synchrony"; Fig. 6D). Ripple event synchrony was more widespread, with $\sim 40 \%$ of the large-amplitude events ( $>7$ SDs at both reference and referred sites) propagating up to $5 \mathrm{~mm}$, while the majority of $<7 \mathrm{SD}$ events remained largely local. Beyond 2 mm distance, fewer than $20 \%$ of the $3-5$ SD events were synchronous (Fig. $6 D$ ). The extent of synchrony was not uniform along the septotemporal axis. If one of the recording sites of the pair was in the temporal segment, ripple event synchrony was smaller and associated with a larger variance at nearly all distances compared to similar distances within the same hippocampal segment (Fig. $6 D$, compare red, blue dots).

The third comparison examined the amplitude attenuation of the ripple events in a fixed time window. This comparison addressed the issue of synchronous activity experienced by downstream targets upon which the CAl outputs converge. The strength of the correlation between ripple events was determined by comparing the amplitude of the Morlet wavelet transform at the time of peak amplitude in the reference ripple event and then taking the mean of the $120-180 \mathrm{~Hz}$ band (Fig. $6 E$ ). The amplitude of the ripple event showed a rapid decrease with distance, indicating that ripple events are locally generated. When largeamplitude ripple events ( $>7$ SDs at both reference and referred sites) were compared, the relative attenuation with distance was steeper compared to smaller-amplitude ripple events (Fig. $6 F$ ).

A surrogate of increased power in the ripple frequency band is the concurrent increase in spiking synchrony (Csicsvari et al., 1999; Schomburg et al., 2012). Since action potentials are the critical carriers of neuronal information, we calculated ripple event triggered MUA for all electrode pairs and plotted the gain in MUA firing activity as a function of septotemporal axis distance between the electrodes (Fig. 7). Similar to the LFP ripple events (Fig. 6D), the ripple triggered gain in MUA was attenuated by $\sim 50 \%$ along the $5 \mathrm{~mm}$ septointermediate length, but a stronger reduction was observed between the septal/intermediate and temporal segments.

For the quantification of the speed of ripple event propagation, we measured either the time shift of the first peak of the cross-correlation of ripples (100-250 Hz-filtered LFPs) or the time difference between the peaks of the Morlet wavelet ampli- 
A
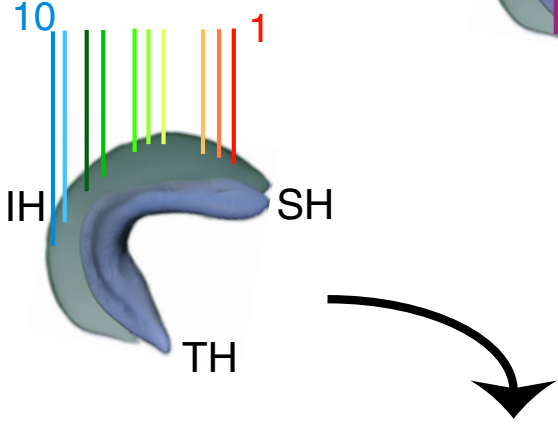
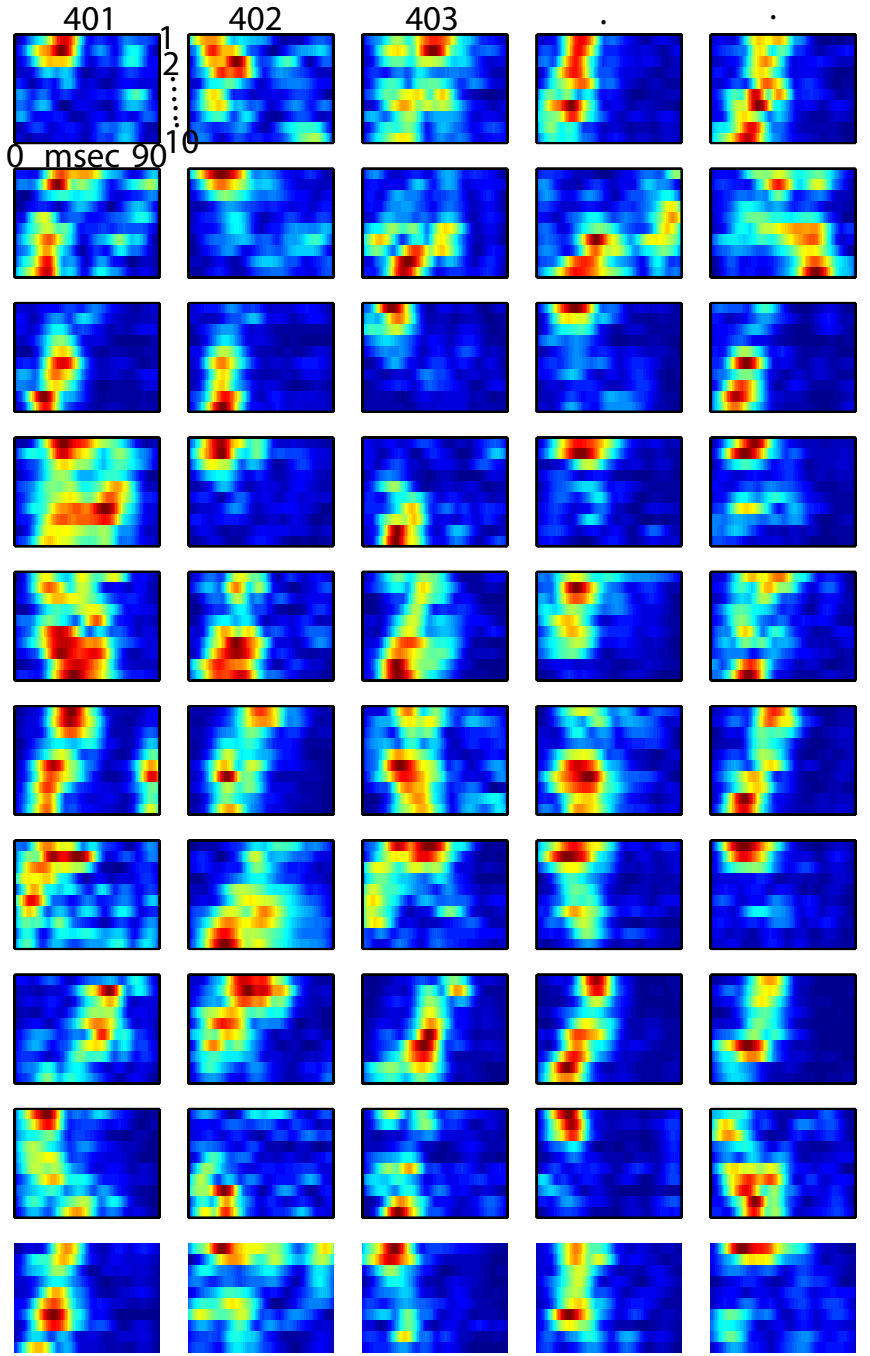

Figure 5. Variability of spatial extent and propagation of ripple events. $\boldsymbol{A}, 0$ ne hundred successive ripple events (401-500) detected at 10 recording sites in the septal hippocampal (SH) and intermediate hippocampal (IH) segments. Each row represents the color-coded amplitude of ripple wavelet (averaged over 120-180 Hz). Note the large event-to-event variability of both spatial spread and direction of ripple propagation. $\boldsymbol{B}$, Examples (35 successive events) recorded from the SH, IH, and temporal hippocampal (TH) segments. Note that ripples in $\mathrm{TH}$ occur mostly in isolation. 
A

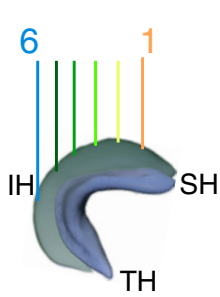

B

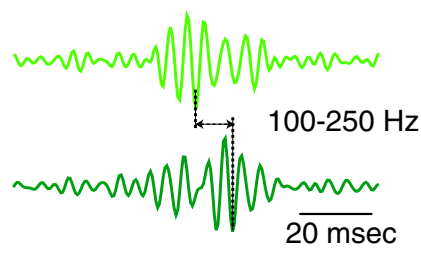

E
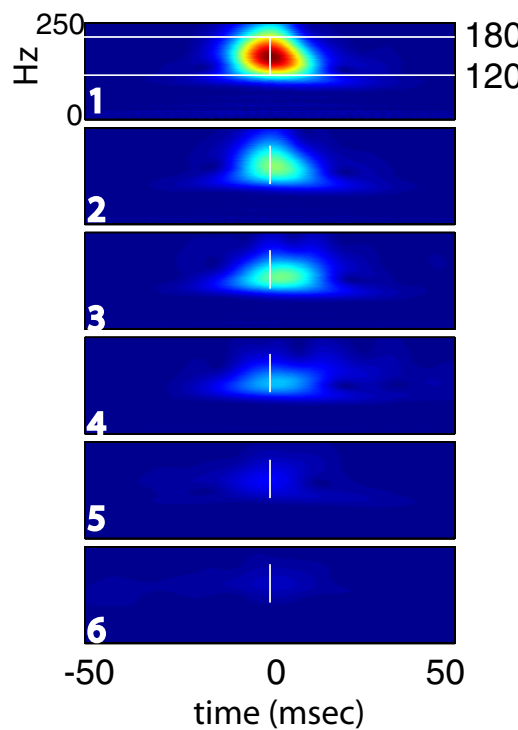
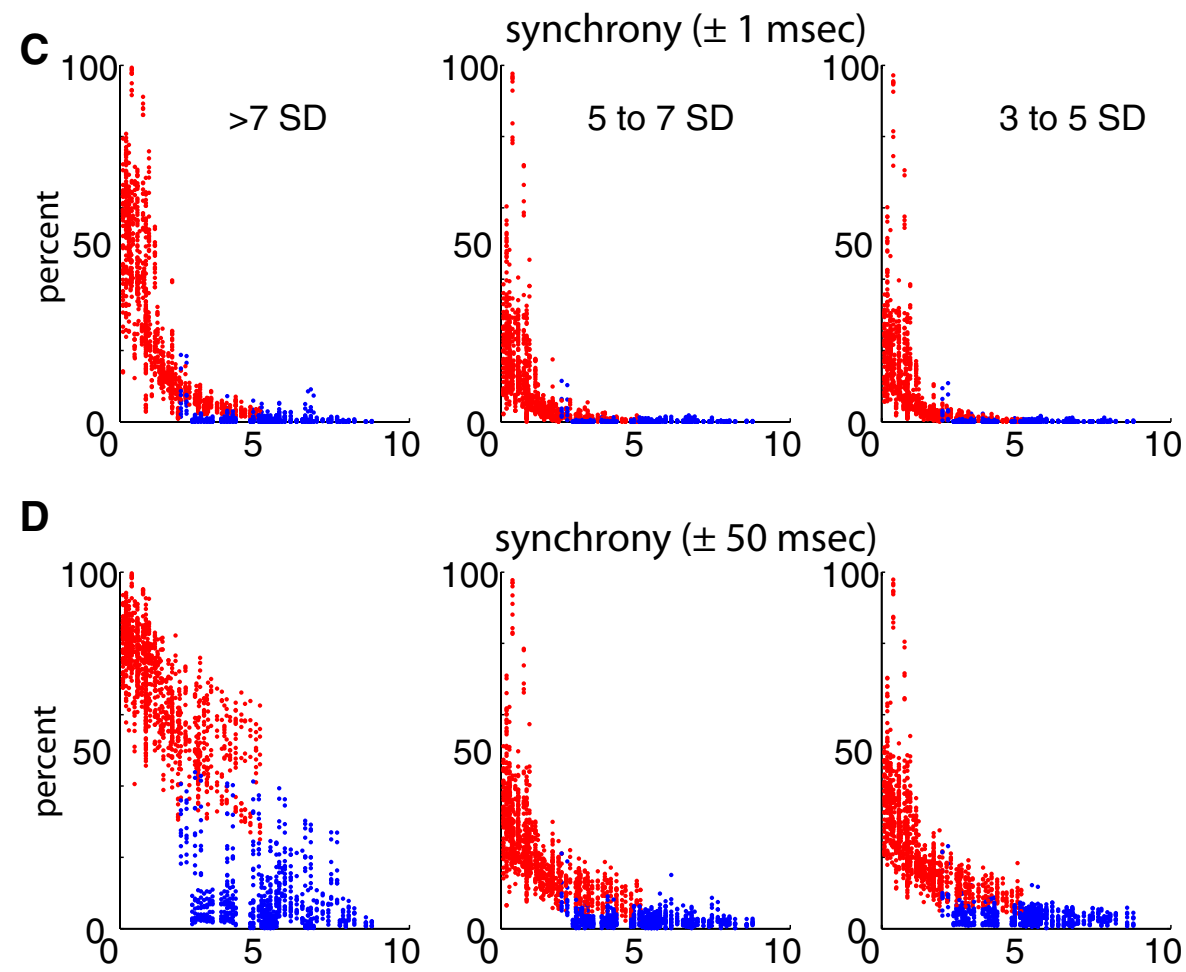

$\mathbf{F}$
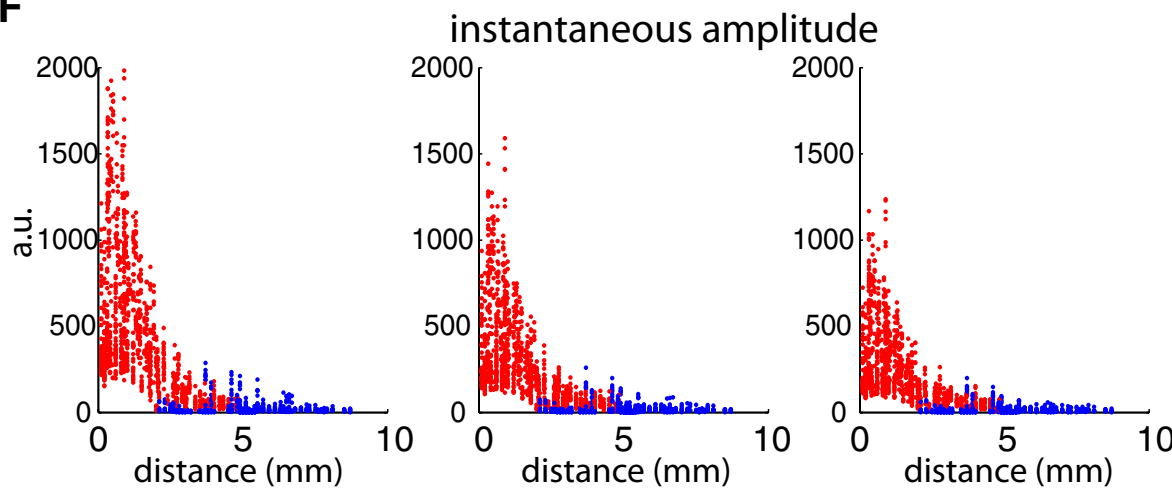

Figure 6. Most CA1 ripples are spatially confined. $A$, An example rat showing the recording locations along the septotemporal axis. SH, Septal hippocampus; IH, intermediate hippocampus; TH, temporal hippocampus. $\boldsymbol{B}$, Single ripple events recorded from two sites. The temporal delay between the largest amplitude troughs are measured. $\boldsymbol{C}$, Spatial synchrony of ripple waves. The percentage of ripple events detected in the referred electrode within $\pm 1 \mathrm{~ms}$ of a ripple event in the reference electrode is plotted as a function of distance between the electrodes. Each dot is based on a single recording session. Dots are colored red if both electrodes of the recording pair were located in the septal-intermediate hippocampus, and blue if one of the electrodes in the pair was in the temporal hippocampus and the other in the septal-intermediate hippocampus. Note that ripple waves in large-amplitude ripple events ( $>7$ SD group; left) spread larger distances than the medium or small ripple events (middle, 5-7 SDs; right, 3-5 SDs). D, Spatial synchrony of ripple events. Same as in $\boldsymbol{C}$, but the referred events were detected within $\pm 50 \mathrm{~ms}$ of the ripple event in the reference electrode. Note the large spatial coverage of large-amplitude ripples ( $>7 S D s$ ) in the septal-intermediate hippocampus (red dots). In contrast, ripple event synchrony between septal-intermediate and temporal sites at similar distances $(2.5$ to $5 \mathrm{~mm}$ ) was low (blue). $\boldsymbol{E}$, An example continuous Morlet wavelet transform during a single ripple event centered on the ripple at site 1 (as in $\boldsymbol{A}$ ). Note rapid attenuation of the ripple event amplitude with distance. $\boldsymbol{F}$, Ripple event amplitude attenuation over distance. Ripple amplitude (at 0 time bin and mean over the $120-180$ $\mathrm{Hz}$ range) was measured at all referred sites during each ripple event in the reference channel, and the means are plotted as a function of distance between the reference and referred electrodes (same color code as in $\boldsymbol{C}, \boldsymbol{D})$.

tude between two recording sites and plotted these as a function of distance (Fig. 8A). Since ripples could sweep either in the septotemporal or temporoseptal direction (Figs. 4, 5), averaging across all trials may not reveal the true speed of travel. Therefore, we first separated the ripple events by septotemporal versus temporoseptal sequences of activation before measuring the absolute time difference between the ripple amplitude maxima at pairs of recording sites against the distance between sites (Xu et al., 2007). The estimated speed of propagation in the septotemporal direction was somewhat faster for the largest amplitude ripple events ( $>7$ SDs, $0.37 \mathrm{~mm} / \mathrm{ms}$ ) than for the smaller-amplitude events
(5-7 SDs, $0.36 \mathrm{~mm} / \mathrm{ms} ; 3-5 \mathrm{SDs}, 0.33 \mathrm{~mm} / \mathrm{ms}$ ). The propagation speed for $>7$ SD events differed significantly from the speed of 3-5 SD events ( $p<0.02$; shuffling test; see Materials and Methods). The ripple propagation speeds in the temporoseptal direction were similar [ $>7 \mathrm{SDs}, 0.40 \mathrm{~mm} / \mathrm{ms} ; 5-7 \mathrm{SDs}, 0.36 \mathrm{~mm} / \mathrm{ms}$, 3-5 SDs, $0.33 \mathrm{~mm} / \mathrm{ms}$; speed of $>7 \mathrm{SD}$ events differed from that of 5-7 SD events $(p<0.006)$ and 3-5 SD events $(p<0.001)]$. When comparing ripple propagation speed for the septotemporal versus temporoseptal directions within the same amplitude groups, only the large-amplitude events ( $>7$ SDs) showed a significant difference $(p<0.001$; shuffling test). The delays between 


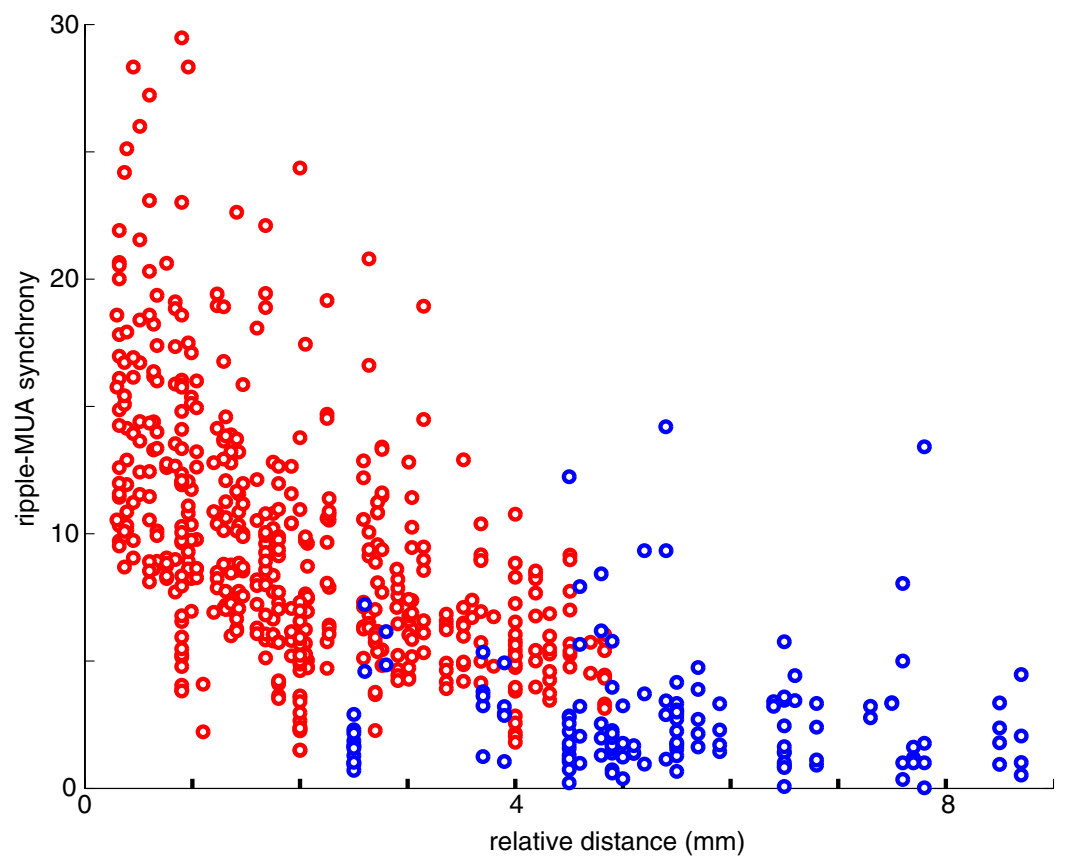

Figure 7. Spatial synchrony of unit firing during ripples. The magnitude of the normalized central peak of the cross-correlogram between a reference LFP ripple ( $>7$ SDs) and unit firing at a referred site (inset) was calculated and plotted as a function of the relative distance between the recording electrodes. Note larger spatial coverage of ripple-unit synchrony in the $\mathrm{SH}$ and $\mathrm{IH}$ (red dots) relative to SH/IH versus TH pairs (blue dots). SH, Septal hippocampus; IH, intermediate hippocampus; TH, temporal hippocampus.

events in the septal/intermediate and temporal segments were quite variable, however (Fig. $8 B, C$, blue dots), consistent with these segments operating relatively independently.

\section{Discussion}

Our experiments demonstrate that ripples can occur at any level of the septotemporal axis of the hippocampal CA1 region, and the locally generated ripple events are qualitatively similar. From the seed, the ripples can travel either septally or temporally with a speed of $\sim 0.35 \mathrm{~m} / \mathrm{s}$ and invade varying segments, depending on the ripple magnitude. While large-amplitude ripple events can occur synchronously over large distances or can propagate long distances, small-amplitude events, in general, remain relatively local. The amplitude, spatial extent, coherence, and frequency of ripples are, in fact, likely to be causally related (Lindén et al., 2011; Schomburg et al., 2012). Although ripples travel smoothly across the septal and intermediate segments of the hippocampus, most ripples in the temporal segment occur in isolation. Ripples that emerge in the temporal and septal/intermediate poles of the hippocampus are therefore largely independent and broadcast information to their cortical and subcortical targets (Logothetis et al., 2012) at different times.

\section{Ripples are locally generated}

Locally confined ripples have been observed previously (Ylinen et al., 1995; Chrobak and Buzsáki, 1996; Csicsvari et al., 2000), but the spread of ripple activity along the septotemporal axis has not been studied quantitatively. While sharp waves and ripples are strongly coupled physiological events, they can be dissociated (Ylinen et al., 1995; Traub and Bibbig, 2000; Maier et al., 2003; Nimmrich et al., 2005; Nakashiba et al., 2008). The population bursts of spatially distributed CA3 pyramidal neurons give rise to widespread depolarization and firing of CA1 (and CA3) pyramidal cells and specific classes of interneurons (Buzsáki et al., 1992; Ylinen et al., 1995; Csicsvari et al., 1999, 2000; Klausberger et al.,
2003; Klausberger and Somogyi, 2008; Varga et al., 2012). Depending on the magnitude of the depolarization of CA1 neurons, they can generate either a fast gamma (or epsilon; $90-120 \mathrm{~Hz}$ ) or ripple $(130-200 \mathrm{~Hz})$ oscillation in the septal CA1 region, largely reflecting the network resonance properties of this region (Sullivan et al., 2011). The extensive axon collaterals of CA3 pyramidal neurons ( $\mathrm{Li}$ et al., 1994) exert a spatially widespread effect on CA1 neurons, as reflected by sharp waves, but ripples can emerge at single or multiple locations in CA1. Observing individual ripple events at multiple locations revealed various forms of ripple propagation, including locally confined events, sweeping patterns from single or multiple locations, collisions, and reflections similar to propagating events described in the neocortex (Arieli et al., 1996; Roland et al., 2006; Benucci et al., 2007; Xu et al., 2007). Although larger ripple amplitude was linked to more spatially extended activation patterns, the amplitude of the locally recorded events did not always predict whether the event will terminate or continue to travel and grow in amplitude.

The large spatial variability of ripples also suggests that widespread ripple events represent the fusion of multiple, locally emerging events. Every segment of the CA1 region along its long axis could generate ripples. Nearby ripples may be synchronized locally by interneuron and/or gap junction-mediated mechanisms (Ylinen et al., 1995; Traub and Bibbig, 2000; Nimmrich et al., 2005; Taxidis et al., 2012) or by the sparse CA1 collaterals (Memmesheimer, 2010; Maier et al., 2011). The somewhat lower amplitude of ripples in the temporal hippocampus can be explained by decreased activation or synchrony of pyramidal cell spikes and/or the lower density of neurons in the temporal hippocampus (Schomburg et al., 2012). In support of the cell density hypothesis, ripples are of larger amplitude in the mouse, where neurons are more densely packed in the same volume compared to the rat (Buzsáki et al., 2003). Modeling studies also demonstrate the importance of the density of spiking neurons surrounding the recording electrodes for the amplitude of extracellular events (Schomburg et al., 2012). Despite the decreased amplitude, the probability of ripple occurrence was similar along the entire extent of the septotemporal axis when all ripples of $>3$ SDs were considered.

\section{Ripple activity sweeps along the septotemporal axis of the hippocampus}

From the site at which a ripple first arose, subsequent ripples could sequentially follow in the septal or temporal direction, or both. The speed of travel was $\sim 0.35 \mathrm{~m} / \mathrm{s}$, which is comparable to previously reported traveling waves in different cortical areas in vivo, including the primary motor cortex and the visual cortex in rats, ferrets, monkeys, and cats (Arieli et al., 1996; Roland et al., 2006; Rubino et al., 2006; Benucci et al., 2007; Xu et al., 2007) and barrel cortex of guinea pigs and rats (Contreras and Llinas, 2001; Petersen et al., 2003). The speed of ripple propagation was almost twice as fast as that of theta wave-related recruitment of neurons 

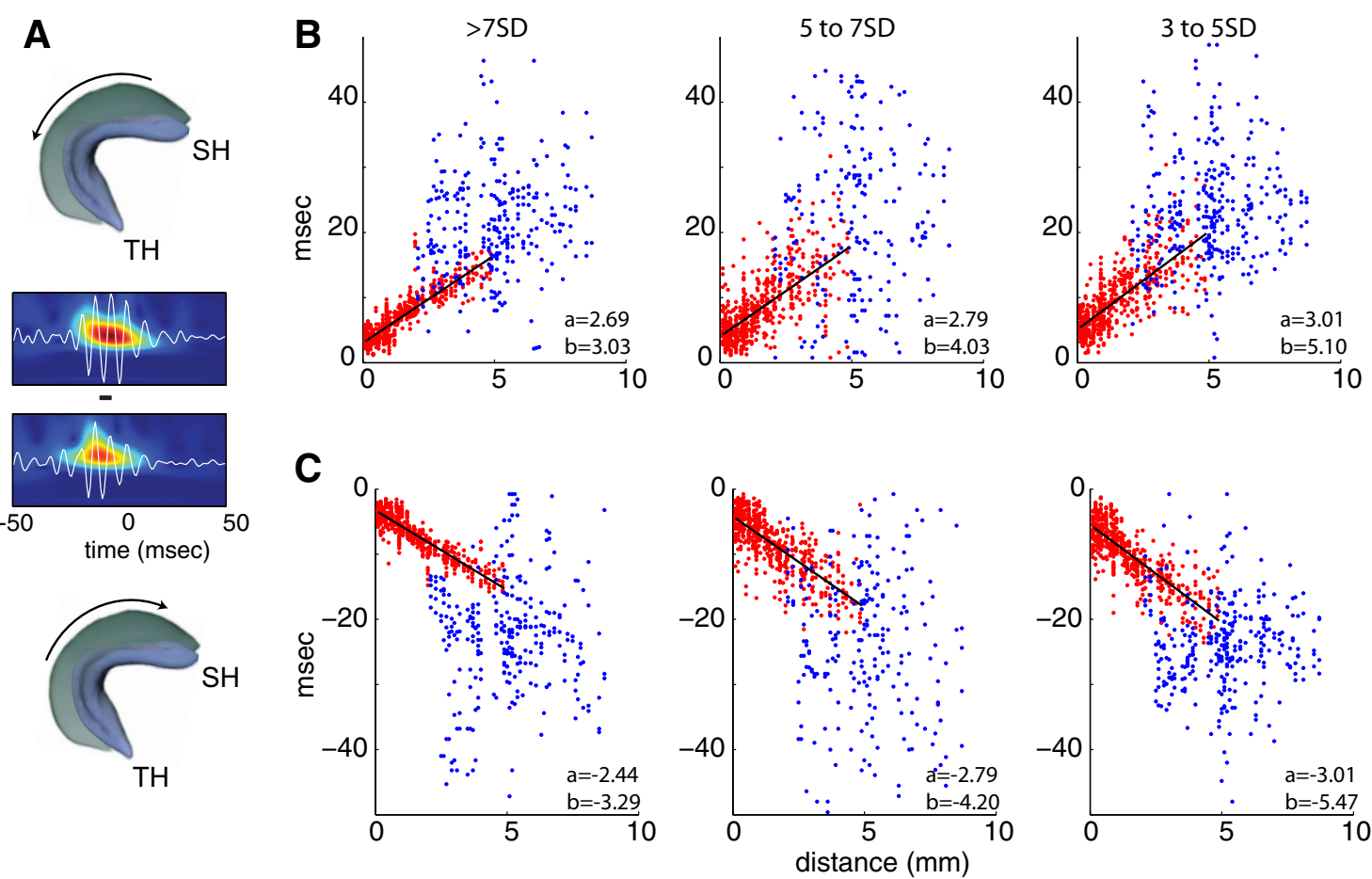

Figure 8. Propagation of ripple events. $\boldsymbol{A}$, Ripple events recorded on electrode pairs and propagating in the temporoseptal (top) and septotermporal (bottom) directions were separated. Examples show ripples at more septal and temporal sites. The horizontal line indicates the time delay between the trough of the largest ripple wave at each site. $\boldsymbol{B}$, Delays between more septal reference electrode and more temporal referred electrode, obtained from wavelet amplitude maxima. $\boldsymbol{C}$, Same as $\boldsymbol{B}$, but shows delays between more temporal reference location and more septal referred location. Blue dots indicate that one electrode of the pair was in the temporal and the other in the septal-intermediate hippocampus. Regression lines for red dots (pairs from the septal and intermediate hippocampus) are shown in black. $b$, y-coordinate intercept; $a$, slope. SH, Septal hippocampus; TH, temporal hippocampus.

(Lubenov and Siapas, 2009; Patel et al., 2012; $0.16 \mathrm{~m} / \mathrm{s}$ ) or in the longitudinal in vitro slice of the CA3 region (Miles et al., 1988). The twofold to fourfold gain of excitation during ripples (Csicsvari et al., 1999) may partially explain the greater propagation speed relative to theta oscillations.

We hypothesize that the propagation mechanisms of ripple events largely reside in the extensive recurrent collaterals of the CA3 neurons (Ishizuka et al., 1990; Li et al., 1994) so that each sharp-wave event is a sweep in space, but individual ripple waves reflect local interactions between CA1 pyramidal cells and interneurons. In support of this hypothesis, low-amplitude ripple events failed to propagate far from their initiation site, whereas roughly half of all high-amplitude events ( $>7 \mathrm{SDs}$ ) corresponded to ripple activity along the entire septal and intermediate segments of the hippocampus exhibited ripples (Fig. 6D). This indicates that widespread excitation, rather than locally mediated interactions, was responsible for the activity sweeps. An alternative substrate for ripple event propagation is the sparse but nevertheless important recurrent collaterals among CA1 pyramidal cells (Deuchars and Thomson, 1996; Memmesheimer, 2010; Maier et al., 2011), or the hypothesized electrical connections between CA1 pyramidal cells (Draguhn et al., 1998; Traub and Bibbig, 2000). Yet another possibility is the GABAergic and sparse glutamatergic septohippocampal projection (Freund and Antal, 1988; Hur et al., 2009).

\section{Hippocampus-neocortical communication by ripples}

A topographic organization exists between different segments of the hippocampus and the neocortex by way of the entorhinal cortical interface (Witter et al. 1989; Petrovich et al., 2001; Amaral and Lavanex, 2007). On the basis of anatomical, lesion, physiological, and fMRI studies, two main communication streams between the hippocampus and the neocortex have been postulated (Suzuki and Amaral, 1994; Burwell and Amaral, 1998; Dolorfo and Amaral, 1998; Chrobak and Amaral, 2007; Ranganath and Ritchey, 2012). The septal hippocampus is more strongly connected to the (dorso)medial entorhinal cortex and the postrhinal cortex (rodent homolog of the parahippocampal cortex in primates), whereas the ventral hippocampus, lateral entorhinal cortex, and perirhinal cortex form a relatively independent stream (Ranganath and Ritchey, 2012). In turn, the parahippocampal cortex communicates mainly with the "default network" (Raichle et al., 2001), while the perirhinal cortex has weaker connections with the default network but stronger connections to the lateral orbitofrontal cortex and the anterior ventrolateral temporal cortex (Ranganath and Ritchey, 2012). The consequence of this anatomically orthogonalized input is that the different segments of the hippocampus communicate with largely different, although overlapping, neocortical and subcortical domains.

Under the framework that hippocampal ripples participate in sleep and rest-related consolidation of memory traces (Buzsáki, 1989; Wilson and McNaughton, 1994; Girardeau et al., 2009), the locally emerging ripples and the rarity of ripple synchrony between the two poles of the hippocampus suggest that the localized activity in different segments of the hippocampus serves to return segregated information to separate cortical systems. Although spatial information is also present in the temporal hippocampus, discrete place cells are rare (Kjelstrup et al. 2008; Royer et al., 2010). Instead, pyramidal neurons in the temporal quadrant reflect progressively increasing representations of emotional memory, and goal or reward directedness (Kjelstrup et al. 2002; Royer et al., 2010). Further support for this view comes from our observations that the temporal segment of the hippocampus behaved 
somewhat disconnected from the rest of the structure. Ripple coherence and co-occurrence between temporal sites and sites in the septal and intermediate hippocampus were both significantly less than at identical distances in the septal and intermediate segments. This was also true for propagation of ripple events to and from the temporal sites. The relatively isolated nature of the temporal segment is also reflected by the abrupt decrease of theta coherence between temporal and septal/intermediate sites and the decreased speed modulation of theta power in the temporal segment (Hinman et al., 2011; Patel et al., 2012). The functional isolation of the temporal segment is likely important because in primates the temporal segment grows disproportionally to become the uncus and body of the hippocampus, parts that communicate with the enlarged associational cortices, including the prefrontal cortical areas and the amygdala (Lavenex and Amaral, 2000; Royer et al., 2010; Ranganath and Ritchey, 2012).

An alternative view is that the rare but present septotemporally synchronous events can permit the hippocampal ripples to integrate information conveyed by the two cortical streams to the septal and temporal parts of the hippocampus. Focal ripples may assist in segregation, while the septotemporally synchronous ripple events may serve to integrate spatial and nonspatial information as it is routed back to the neocortex. Such flexible segregation-integration mechanisms may assist with off-line categorization of hippocampofugal information (McClelland et al., 1995). Mixing of intrahippocampal neuronal information may be further coordinated by the waking experience dependence of ripple propagation. Indeed, further investigation of the coordination of sharp-wave ripples between the two poles is needed during and following behavioral tasks that effectively use both poles of the hippocampus, with salient spatial, contextual, and emotional memory components.

\section{References}

Adhikari A, Topiwala MA, Gordon JA (2011) Single units in the medial prefrontal cortex with anxiety-related firing patterns are preferentially influenced by ventral hippocampal activity. Neuron 71:898-910. CrossRef Medline

Amaral D, Lavenex P (2007) Hippocampal neuroanatomy. In: The hippocampus book (Andersen P, Morris R, Amaral D, Bliss T, O'Keefe J, eds), pp 37-114. New York: Oxford UP.

Arieli A, Sterkin A, Grinvald A, Aertsen A (1996) Dynamics of ongoing activity: explanation of the large variability in evoked cortical responses. Science 273:1868-1871. CrossRef Medline

Axmacher N, Elger CE, Fell J (2008) Ripples in the medial temporal lobe are relevant for human memory consolidation. Brain 131:1806-1817. CrossRef Medline

Benucci A, Frazor RA, Carandini M (2007) Standing waves and traveling waves distinguish two circuits in visual cortex. Neuron 55:103-117. CrossRef Medline

Buhl DL, Buzsáki G (2005) Developmental emergence of hippocampal fastfield "ripple" oscillations in the behaving rat pups. Neuroscience 134: 1423-1430. CrossRef Medline

Burwell RD, Amaral DG (1998) Cortical afferents of the perirhinal, postrhinal, and entorhinal cortices of the rat. J Comp Neurol 398:179-205. CrossRef Medline

Buzsáki G (1986) Hippocampal sharp waves: their origin and significance. Brain Res 398:242-252. CrossRef Medline

Buzsáki G (1989) Two-stage model of memory trace formation: a role for "noisy" brain states. Neuroscience 31:551-570. CrossRef Medline

Buzsáki G (1996) The hippocampo-neocortical dialogue. Cereb Cortex 6:81-92. CrossRef Medline

Buzsáki G, Leung LW, Vanderwolf CH (1983) Cellular bases of hippocampal EEG in the behaving rat. Brain Res Rev 287:139-171. Medline

Buzsáki G, Horváth Z, Urioste R, Hetke J, Wise K (1992) High-frequency network oscillation in the hippocampus. Science 256:1025-1027. CrossRef Medline

Buzsáki G, Buhl DL, Harris KD, Csicsvari J, Czéh B, Morozov A (2003) Hippocampal network patterns of activity in the mouse. Neuroscience 116:201-211. CrossRef Medline

Chrobak JJ, Amaral DG (2007) Entorhinal cortex of the monkey: VII. intrinsic connections. J Comp Neurol 500:612-633. CrossRef Medline

Chrobak JJ, Buzsáki G (1996) High-frequency oscillations in the output networks of the hippocampal-entorhinal axis of the freely behaving rat. J Neurosci 16:3056-3066. Medline

Contreras D, Llinas R (2001) Voltage-sensitive dye imaging of neocortical spatiotemporal dynamics to afferent activation frequency. J Neurosci 21: 9403-9413. Medline

Csicsvari J, Hirase H, Czurkó A, Mamiya A, Buzsáki G (1999) Fast network oscillations in the hippocampal CA1 region of the behaving rat. J Neurosci 19:RC20. Medline

Csicsvari J, Hirase H, Mamiya A, Buzsáki G (2000) Ensemble patterns of hippocampal CA3-CA1 neurons during sharp wave-associated population events. Neuron 28:585-594. CrossRef Medline

Deadwyler SA, Bunn T, Hampson RE (1996) Hippocampal ensemble activity during spatial delayed-nonmatch-to-sample performance in rats. J Neurosci 16:354-372. Medline

Deuchars J, Thomson AM (1996) CAl pyramid-pyramid connections in rat hippocampus in vitro: dual intracellular recordings with biocytin filling. Neuroscience 74:1009-1018. CrossRef Medline

Diba K, Buzsáki G (2007) Forward and reverse hippocampal place-cell sequences during ripples. Nat Neurosci 10:1241-1242. CrossRef Medline

Dolorfo CL, Amaral DG (1998) Entorhinal cortex of the rat: topographic organization of the cells of origin of the perforant path projection to the dentate gyrus. J Comp Neurol 398:49-82. CrossRef Medline

Dragoi G, Tonegawa S (2011) Preplay of future place cell sequences by hippocampal cellular assemblies. Nature 469:397-401. CrossRef Medline

Dragoi G, Tonegawa S (2013) Distinct preplay of multiple novel spatial experiences in the rat. Proc Natl Acad Sci U S A 110:9100-9105. CrossRef Medline

Draguhn A, Traub RD, Schmitz D, Jefferys JG (1998) Electrical coupling underlies high-frequency oscillations in the hippocampus in vitro. Nature 394:189-192. CrossRef Medline

Dupret D, O’Neill J, Pleydell-Bouverie B, Csicsvari J (2010) The reorganization and reactivation of hippocampal maps predict spatial memory performance. Nat Neurosci 13:995-1002. CrossRef Medline

Ego-Stengel V, Wilson MA (2010) Disruption of ripple-associated hippocampal activity during rest impairs spatial learning in the rat. Hippocampus 20:1-10. Medline

Eschenko O, Ramadan W, Mölle M, Born J, Sara SJ (2008) Sustained increase in hippocampal sharp-wave ripple activity during slow-wave sleep after learning. Learn Mem 15:222-228. CrossRef Medline

Foster DJ, Wilson MA (2006) Reverse replay of behavioural sequences in hippocampal place cells during the awake state. Nature 440:680-683. CrossRef Medline

Freund TF, Antal M (1988) GABA-containing neurons in the septum control inhibitory interneurons in the hippocampus. Nature 336:170-173. CrossRef Medline

Girardeau G, Benchenane K, Wiener SI, Buzsáki G, Zugaro MB (2009) Selective suppression of hippocampal ripples impairs spatial memory. Nat Neurosci 12:1222-1223. CrossRef Medline

Hampson RE, Simeral JD, Deadwyler SA (1999) Distribution of spatial and nonspatial information in dorsal hippocampus. Nature 402:610-614. CrossRef Medline

Hazan L, Zugaro M, Buzsáki G (2006) Klusters, NeuroScope, NDManager: a free software suite for neurophysiological data processing and visualization. J Neurosci Methods 155:207-216. CrossRef Medline

Hinman JR, Penley SC, Long LL, Escabí MA, Chrobak JJ (2011) Septotemporal variation in dynamics of theta: speed and habituation. J Neurophysiol 105:2675-2686. CrossRef Medline

Hur EE, Edwards RH, Rommer E, Zaborszky L (2009) Vesicular glutamate transporter 1 and vesicular glutamate transporter 2 synapses on cholinergic neurons in the sublenticular gray of the rat basal forebrain: a doublelabel electron microscopic study. Neuroscience 164:1721-1731. CrossRef Medline

Ishizuka N, Weber J, Amaral DG (1990) Organization of intrahippocampal 
projections originating from CA3 pyramidal cells in the rat. J Comp Neurol 295:580-623. CrossRef Medline

Ji D, Wilson MA (2007) Coordinated memory replay in the visual cortex and hippocampus during sleep. Nat Neurosci 10:100-107. CrossRef Medline

Jung MW, Wiener SI, McNaughton BL (1994) Comparison of spatial firing characteristics of units in dorsal and ventral hippocampus of the rat. J Neurosci 14:7347-7356. Medline

Karlsson MP, Frank LM (2008) Network dynamics underlying the formation of sparse, informative representations in the hippocampus. J Neurosci 28:14271-14281. CrossRef Medline

Karlsson MP, Frank LM (2009) Awake replay of remote experiences in the hippocampus. Nat Neurosci 12:913-918. CrossRef Medline

Kjelstrup KB, Solstad T, Brun VH, Hafting T, Leutgeb S, Witter MP, Moser EI, Moser MB (2008) Finite scale of spatial representation in the hippocampus. Science 321:140-143. CrossRef Medline

Kjelstrup KG, Tuvnes FA, Steffenach HA, Murison R, Moser EI, Moser MB (2002) Reduced fear expression after lesions of the ventral hippocampus. Proc Natl Acad Sci U S A 99:10825-10830. CrossRef Medline

Klausberger T, Somogyi P (2008) Neuronal diversity and temporal dynamics: the unity of hippocampal circuit operations. Science 321:53-57. CrossRef Medline

Klausberger T, Magill PJ, Márton LF, Roberts JD, Cobden PM, Buzsáki G, Somogyi P (2003) Brain-state- and cell-type-specific firing of hippocampal interneurons in vivo. Nature 421:844-848. CrossRef Medline

Kudrimoti HS, Barnes CA, McNaughton BL (1999) Reactivation of hippocampal cell assemblies: effects of behavioral state, experience, and EEG dynamics. J Neurosci 19:4090-4101. Medline

Lavenex P, Amaral DG (2000) Hippocampal-neocortical interaction: a hierarchy of associativity. Hippocampus 10:420-430. CrossRef Medline

Lee AK, Wilson MA (2002) Memory of sequential experience in the hippocampus during slow wave sleep. Neuron 36:1183-1194. CrossRef Medline

Li XG, Somogyi P, Ylinen A, Buzsáki G (1994) The hippocampal CA3 network: an in vivo intracellular study. J Comp Neurol 339:181-208. CrossRef Medline

Lindén H, Tetzlaff T, Potjans TC, Pettersen KH, Grün S, Diesmann M, Einevoll GT (2011) Modeling the spatial reach of the LFP. Neuron 72: 859-872. CrossRef Medline

Logothetis NK, Eschenko O, Murayama Y, Augath M, Steudel T, Evrard HC, Besserve M, Oeltermann A (2012) Hippocampal-cortical interaction during periods of subcortical silence. Nature 491:547-553. CrossRef Medline

Lubenov EV, Siapas AG (2008) Decoupling through synchrony in neuronal circuits with propagation delays. Neuron 58:118-131. CrossRef Medline

Lubenov EV, Siapas AG (2009) Hippocampal theta oscillations are travelling waves. Nature 459:534-539. CrossRef Medline

Maier N, Nimmrich V, Draguhn A (2003) Cellular and network mechanisms underlying spontaneous sharp wave-ripple complexes in mouse hippocampal slices. J Physiol 550:873-887. CrossRef Medline

Maier N, Tejero-Cantero A, Dorrn AL, Winterer J, Beed PS, Morris G, Kempter R, Poulet JF, Leibold C, Schmitz D (2011) Coherent phasic excitation during hippocampal ripples. Neuron 72:137-152. CrossRef Medline

Maurer AP, Vanrhoads SR, Sutherland GR, Lipa P, McNaughton BL (2005) Self-motion and the origin of differential spatial scaling along the septotemporal axis of the hippocampus. Hippocampus 15:841-852. CrossRef Medline

McClelland JL, McNaughton BL, O’Reilly RC (1995) Why there are complementary learning systems in the hippocampus and neocortex: insights from the successes and failures of connectionist models of learning and memory. Psychol Rev 102:419-457. CrossRef Medline

Memmesheimer RM (2010) Quantitative prediction of intermittent highfrequency oscillations in neural networks with supralinear dendritic interactions. Proc Natl Acad Sci U S A 107:11092-11097. CrossRef Medline

Miles R, Traub RD, Wong RK (1988) Spread of synchronous firing in longitudinal slices from the CA3 region of the hippocampus. J Neurophysiol 60:1481-1496. Medline

Mizuseki K, Diba K, Pastalkova E, Buzsáki G (2011) Hippocampal CA1 pyramidal cells form functionally distinct sublayers. Nat Neurosci 14:11741181. CrossRef Medline
Mölle M, Born J (2009) Hippocampus whispering in deep sleep to prefrontal cortex-for good memories? Neuron 61:496-498. Medline

Nádasdy Z, Hirase H, Czurkó A, Csicsvari J, Buzsáki G (1999) Replay and time compression of recurring spike sequences in the hippocampus. J Neurosci 19:9497-9507. Medline

Nakashiba T, Young JZ, McHugh TJ, Buhl DL, Tonegawa S (2008) Transgenic inhibition of synaptic transmission reveals role of CA3 output in hippocampal learning. Science 319:1260-1264. CrossRef Medline

Nimmrich V, Maier N, Schmitz D, Draguhn A (2005) Induced sharp waveripple complexes in the absence of synaptic inhibition in mouse hippocampal slices. J Physiol 563:663-670. CrossRef Medline

Nokia MS, Mikkonen JE, Penttonen M, Wikgren J (2012) Disrupting neural activity related to awake-state sharp wave-ripple complexes prevents hippocampal learning. Front Behav Neurosci 6:84. Medline

O'Keefe J (2007) Hippocampal Neurophysiology in the behaving animal. In: The hippocampus book. (Andersen P, Morris R, Amaral D, Bliss T, O'Keefe J, eds), pp 475-548. New York: Oxford UP.

O'Keefe J, Nadel L (1978) The hippocampus as a cognitive map. Oxford, UK: Oxford UP.

O'Neill J, Senior T, Csicsvari J (2006) Place-selective firing of CA1 pyramidal cells during sharp wave/ripple network patterns in exploratory behavior. Neuron 49:143-155. CrossRef Medline

O'Neill J, Senior TJ, Allen K, Huxter JR, Csicsvari J (2008) Reactivation of experience-dependent cell assembly patterns in the hippocampus. Nat Neurosci 11:209-215. CrossRef Medline

Patel J, Fujisawa S, Berényi A, Royer S, Buzsáki G (2012) Traveling theta waves along the entire septotemporal axis of the hippocampus. Neuron 75:410-417. CrossRef Medline

Petersen CC, Hahn TT, Mehta M, Grinvald A, Sakmann B (2003) Interaction of sensory responses with spontaneous depolarization in layer $2 / 3$ barrel cortex. Proc Natl Acad Sci U S A 100:13638-13643. CrossRef Medline

Petrovich GD, Canteras NS, Swanson LW (2001) Combinatorial amygdalar inputs to hippocampal domains and hypothalamic behavior systems. Brain Res Rev 38:247-289. CrossRef Medline

Raichle ME, MacLeod AM, Snyder AZ, Powers WJ, Gusnard DA, Shulman GL (2001) A default mode of brain function. Proc Natl Acad Sci U S A 98:676-682. Medline

Ramadan W, Eschenko O, Sara SJ (2009) Hippocampal sharp wave/ripples during sleep for consolidation of associative memory. PLoS One 4:e6697. CrossRef Medline

Ranganath C, Ritchey M (2012) Two cortical systems for memory-guided behaviour. Nat Rev Neurosci 13:713-726. CrossRef Medline

Roland PE, Hanazawa A, Undeman C, Eriksson D, Tompa T, Nakamura H, Valentiniene S, Ahmed B (2006) Cortical feedback depolarization waves: a mechanism of top-down influence on early visual areas. Proc Natl Acad Sci U S A 103:12586-12591. CrossRef Medline

Royer S, Sirota A, Patel J, Buzsáki G (2010) Distinct representations and theta dynamics in dorsal and ventral hippocampus. J Neurosci 30:17771787. CrossRef Medline

Rubino D, Robbins KA, Hatsopoulos NG (2006) Propagating waves mediate information transfer in the motor cortex. Nat Neurosci 9:1549-1557. CrossRef Medline

Schomburg EW, Anastassiou CA, Buzsáki G, Koch C (2012) The spiking component of oscillatory extracellular potentials in the rat hippocampus. J Neurosci 32:11798-11811. CrossRef Medline

Segal M, Richter-Levin G, Maggio N (2010) Stress-induced dynamic routing of hippocampal connectivity: a hypothesis. Hippocampus 20:13321338. CrossRef Medline

Siapas AG, Wilson MA (1998) Coordinated interactions between hippocampal ripples and cortical spindles during slow-wave sleep. Neuron 21:1123-1128. CrossRef Medline

Singer AC, Frank LM (2009) Rewarded outcomes enhance reactivation of experience in the hippocampus. Neuron 64:910-921. CrossRef Medline

Skaggs WE, McNaughton BL (1996) Replay of neuronal firing sequences in rat hippocampus during sleep following spatial experience. Science 271: 1870-1873. CrossRef Medline

Sullivan D, Csicsvari J, Mizuseki K, Montgomery S, Diba K, Buzsáki G (2011) Relationships between hippocampal sharp waves, ripples, and fast gamma oscillation: influence of dentate and entorhinal cortical activity. J Neurosci 31:8605-8616. CrossRef Medline 
Suzuki WA, Amaral DG (1994) Topographic organization of the reciprocal connections between the monkey entorhinal cortex and the perirhinal and parahippocampal cortices. J Neurosci 14:1856-1877. Medline

Taxidis J, Coombes S, Mason R, Owen MR (2012) Modeling sharp waveripple complexes through a CA3-CA1 network model with chemical synapses. Hippocampus 22:995-1017. CrossRef Medline

Traub RD, Bibbig A (2000) A model of high frequency ripples in the hippocampus based on synaptic coupling plus axon-axon gap junctions between pyramidal neurons. J Neurosci 20:2086-2093. Medline

Varga C, Golshani P, Soltesz I (2012) Frequency-invariant temporal ordering of interneuronal discharges during hippocampal oscillations in awake mice. Proc Natl Acad Sci U S A 109:E2726-E34. CrossRef Medline

Wiener SI (1996) Spatial, behavioral and sensory correlates of hippocampal
CA1 complex spike cell activity: implications for information processing functions. Prog Neurobiol 49:335-361. CrossRef Medline

Wilson MA, McNaughton BL (1994) Reactivation of hippocampal ensemble memories during sleep. Science 265:676-679. CrossRef Medline

Witter MP, Groenewegen HJ, Lopes da Silva FH, Lohman AH (1989) Functional organization of the extrinsic and intrinsic circuitry of the parahippocampal region. Prog Neurobiol 33:161-253. CrossRef Medline

Xu W, Huang X, Takagaki K, Wu JY (2007) Compression and reflection of visually evoked cortical waves. Neuron 55:119-129. CrossRef Medline

Ylinen A, Bragin A, Nádasdy Z, Jandó G, Szabó I, Sik A, Buzsáki G (1995) Sharp wave-associated high-frequency oscillation $(200 \mathrm{~Hz})$ in the intact hippocampus: network and intracellular mechanisms. J Neurosci 15:3046. Medline 